\title{
OROFACIAL DYSFUNCTIONS, DRINKING REGIMEN AND QUALITY OF LIFE - LONG-TERM PROSPECTIVE STUDY
}

\author{
Alexandra Pilinová1, Eva Matejičková2, Erika Lenčová ${ }^{1}$, Jana Foltinová ${ }^{3}$, Jiří Pišăa \\ ${ }^{1}$ Institute of Dental Research - 1st Faculty of Medicine of the Charles University in Prague and General University Hospital, Prague, \\ Czech Republic \\ ${ }^{2}$ Private physiotherapeutic practice, Prague, Czech Republic \\ ${ }^{3} \mathrm{HBSW}$, Ltd., Prague, Czech Republic \\ ${ }^{4} T E S O$, Ltd., Prague, Czech Republic
}

\begin{abstract}
SUMMARY
The care for mentally ill patients with combined impairment deals with orofacial dysfunctions of the mentally ill, especially children suffering from Down syndrome and cerebral palsy.

Objective of the study was to assess urine fluoride excretion in disabled patients with orofacial dysfunctions in relation to prevention of dental caries. The urine fluoride concentrations in disabled people were analysed to assess their fluoride exposure and possibly preventive contribution of fluoride intake.

The patients for the study were recruited from the clients of three day-stay establishments from two regions in the Czech Republic. All the clients from the selected establishments were examined except for a small number of clients, whose statutory representatives (usually parents) did not agree with oral examination. Signed informed consents were obtained from the statutory representatives of all the examined patients. Totally 95 mentally disabled patients were examined with the mean age of 11.8 years (ranging from 6 months to 28 years) for orofacial dysfunctions using the Castillo Morales concept. Fluoride concentrations were measured by fluoride-selective electrode. The urine density was measured by means of hydrostatic weighing. The above-mentioned analytical methods were chosen since urine density reflects the overall liquids intake by the person and the fluoride excretion by the urine reflects its intake from all environmental sources. Atypical swallowing act was found in $98 \%$ of the cohort. Mean urine density was $1.038 \mathrm{~g} / \mathrm{ml}$ ranging from 1.002 to 1.069 (77 samples). The mean urine fluoride concentration was $0.816 \mathrm{mg} / \mathrm{l}$ ranging from 0.045 to 3.225 (82 samples).

Orofacial dysfunctions decrease the quality of life. Among other aspects, they influence liquids intake due to an impaired swallowing act. Moreover, patients are often dependent on the assistance of the other persons.
\end{abstract}

Key words: orofacial health, quality of life, drinking regimen, urine density, urine fluoride concentration, impaired swallowing act, liquids intake

Address for correspondence: A. Pilinová, Institute of Dental Research, Vinohradská 48, 120 21, Praha 2, Czech Republic.

E-mail: alex.p@centrum.cz

\section{INTRODUCTION}

One of the issues of public health is the care for disabled mentally ill people with combined impairments. This paper deals with orofacial dysfunctions, which should be addressed on a public health level because they are related to a considerably large population group. This area is specific, because orofacial dysfunctions and oral health of the mentally ill disabled patients, especially children suffering from Down syndrome and cerebral palsy are usually masked by symptoms of the main disease. In $100 \%$ of these patients, disturbances of muscular coordination of facial and neck region are present, which influence breathing, swallowing and other functions of orofacial system $(1,2)$.

Difficulties related to the impaired swallowing act directly influence liquids intake and thus have an impact on the quality of life of the patients. One of the challenges related to orofacial dysfunctions is the swallowing of toothpaste during oral hygiene. This is due to the fact that patients suffering from orofacial dysfunctions have difficulties with rinsing the mouth, being unable to spit out, and the remnants of the toothpaste are swallowed.

Therefore it was necessary to determine the urine fluoride concentrations to estimate fluoride intake. Determination of urine fluoride concentrations is important with regard to the introduction of an individual preventive oral program for this disabled patient.

The fluoride concentrations in the urine are known in children, who used water supplemented with fluoride for the reasons of the prevention of dental caries. It has been well documented that during the period of water fluoridation the children had the urine fluoride concentrations about $1 \mathrm{ppm}$. When these urine fluoride concentrations were found, the preventive effect was a $50 \%$ reduction of teeth affected with dental caries (3). 
The liquids intake in disabled patients with orofacial dysfunctions may be inadequately low due to the patients' specific behavioural patterns such as trying to avoid swallowing. The situation can be further complicated by the fact that the majority of disabled patients, because of their impairment, have limited access to drinks during the day, even though they are able to drink themselves.

The characteristics of the atypical swallowing act are also described in this paper, the urine density and urine fluoride concentrations are presented and different ways of liquids intake (i.e. bottle, spoon, cup) are shown.

\section{MATERIAL AND METHODS}

The patients for the study were recruited from the clients of three day-stay establishments from two regions in the Czech Republic (Prague and Brno cities). All the clients from the selected establishments were examined except for a small number of clients, whose statutory representatives (usually parents) did not agree with oral examination. Signed informed consents were obtained from the statutory representatives of all the patients.

Table 1. Characteristics of examined group

\begin{tabular}{|l|l|l|}
\hline Total & Males & Females \\
\hline 95 & 59 & 36 \\
\hline
\end{tabular}

\begin{tabular}{|l|l|l|l|}
\hline Age & $\mathbf{n}$ & Males & Females \\
\hline Mean & 11.8 & 12.4 & 10.8 \\
\hline SD & 7 & 6.8 & 7.3 \\
\hline Minimum & 0 & 0 & 1 \\
\hline Maximum $^{\star *}$ & 28 & 28 & 24 \\
\hline
\end{tabular}

*According to the WHO classification

${ }^{*}$ Older patients were examined with regard to the generally accepted opinion that orofacial dysfunctions may disappear spontaneously.

Totally 95 mentally disabled patients with the mean age of 11.8 years (ranging from 6 months to 28 years) were orally examined (Table 1). The oral health indices - DMFT (Decayed, Missing and Filled Teeth) and DI-OHI (Debris Index of Oral Hygiene Index) and PMA (Inflammation of Papilla, Marginal and Attached gingiva) were established (4). The orofacial dysfunctions were examined using the Castillo Morales concept $(1,2,5,6)$. Fluoride concentrations were measured by fluoride-selective electrode. The urine density was measured by means of hydrostatic weighing (7). The above-mentioned analytical methods were chosen since urine density reflects the overall liquids intake by the person and the fluoride excretion by the urine reflects its intake from all environmental sources, which was sufficiently documented in the literature (8). The measured concentration of fluoride was extrapolated to the standard density $(1.020 \mathrm{~g} / \mathrm{ml})$ and constant temperature (7).

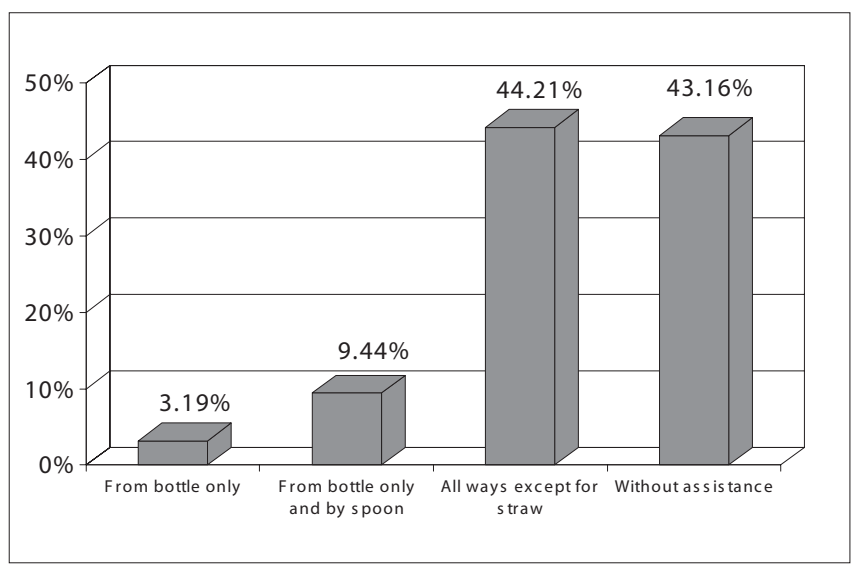

Fig. 1. Liquids administration.

\section{RESULTS}

The $98 \%$ of disabled persons swallowed in an atypical way (i.e. 94 out of 95 examined persons)

The urine density was measured in 77 samples (Table 2); mean density found was $1.038 \mathrm{~g} / \mathrm{ml}$ [standard deviation-(SD) 0.015 , minimum-(min.). value 1.002, maximum-(max.) value 1.069]. The mean fluoride concentration was measured in 88 samples; the mean value was $0.816 \mathrm{mg} / \mathrm{l}$ (SD 0.624 , min. value 0.045 , max. value 3.225 ). The mean extrapolated fluoride concentration was $0.466 \mathrm{mg} / \mathrm{l}$ (SD 0.357, min. value 0.092, max. value 2.77). Only in 77 samples it was possible to extrapolate the fluoride concentration to the density of 1.020 , because of the urine quantity. This is due to the fact that the analysis of fluoride concentration was performed first and if the volume of the urine was low, it was not possible to measure the urine density. With respect to the study design, the urine density was less relevant. In 8 children it was not possible to collect urine samples at all (total number of persons was 95).

Different ways of liquids administration are presented in Fig. 1. The administration of liquids without assistance is possible only in $43.2 \%$ of the patients. All other patients needed some form of assistance, which resulted from an atypical body and face development - these patients had severe orofacial dysfunctions $(9,10,11)$.

Table 2. Urine density and fluoride concentration - 2003

\begin{tabular}{|l|l|l|l|}
\hline & $\begin{array}{l}\text { Urine density at } \\
20^{\circ} \mathrm{C}[\mathrm{g} / \mathrm{ml}]\end{array}$ & $\begin{array}{l}\text { Fluoride con- } \\
\text { centration in the } \\
\text { sample }[\mathrm{mg} / \mathrm{l}]\end{array}$ & $\begin{array}{l}\text { Fluoride } \\
\text { concentration } \\
\text { extrapolated to } \\
\text { the density of } \\
1.020[\mathrm{mg} / \mathrm{l}]\end{array}$ \\
\hline $\mathrm{n}$ & 77 & 82 & 77 \\
\hline Mean & 1.038 & 0.862 & 0.466 \\
\hline $\begin{array}{l}\text { Standard } \\
\text { deviation }\end{array}$ & 0.015 & 0.624 & 0.357 \\
\hline Minimum value & 1.002 & 0.045 & 0.092 \\
\hline Maximum value & 1.069 & 3.225 & 2.771 \\
\hline
\end{tabular}




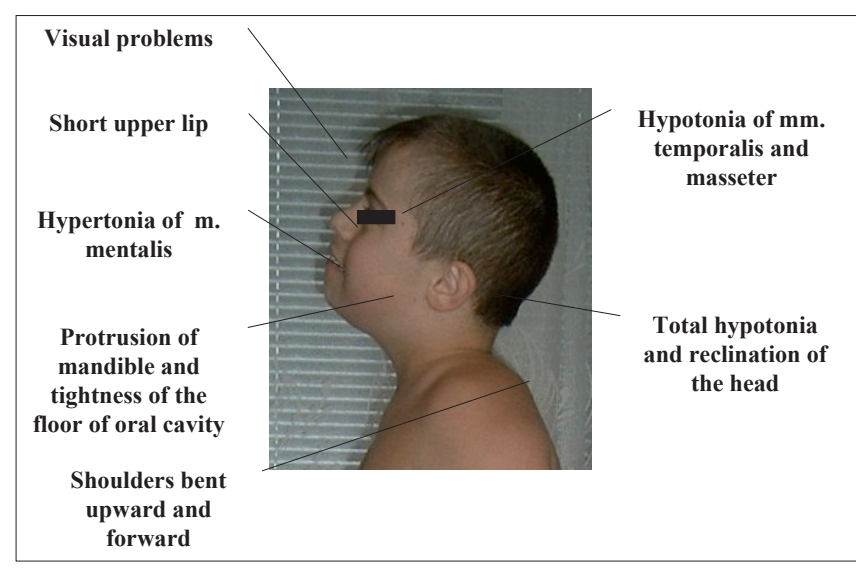

Fig. 2. Atypical swallowing act - 1st phase.

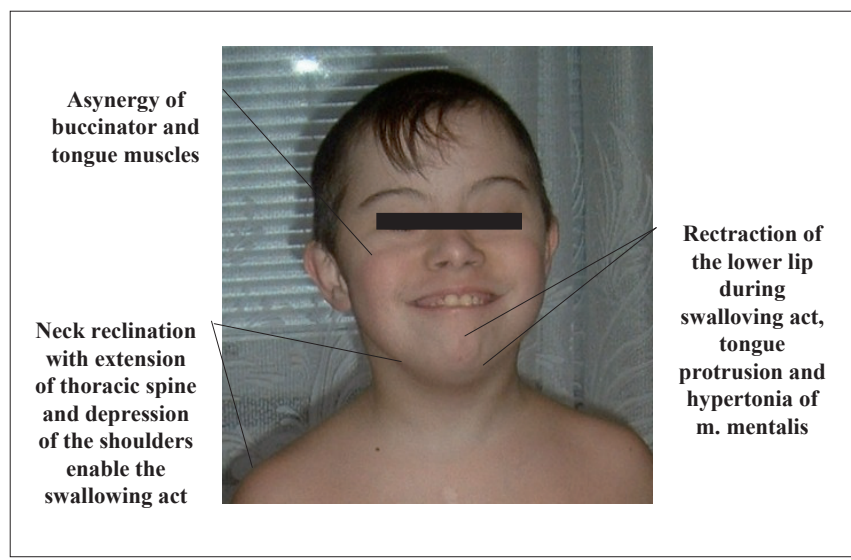

Fig. 3. Atypical swallowing act - 2nd phase.

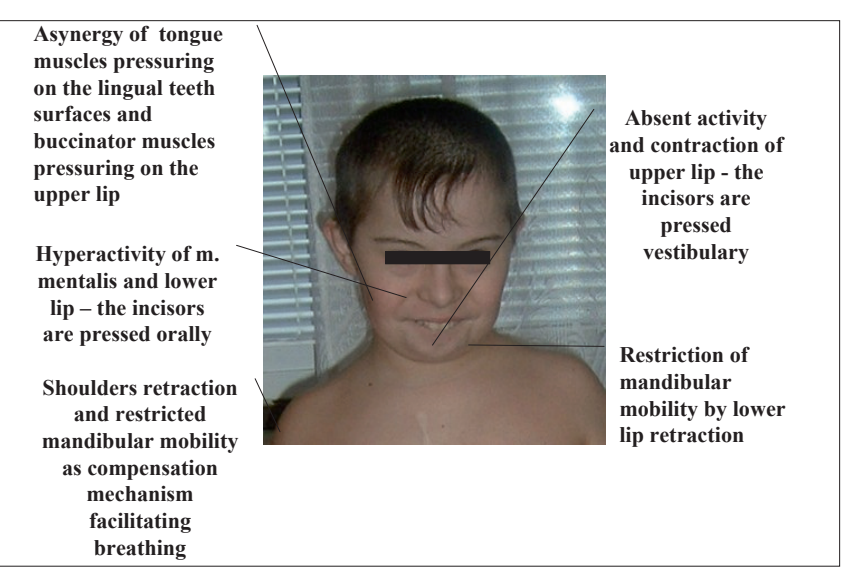

Fig. 4. Atypical swallowing act - 3rd phase.

The atypical swallowing act is documented in Fig. 2, 3, and 4. The illustration of the pathology is considered to be important, since it enables to take an insight in how the quality of life can be affected. The boy suffered from Down syndrome. He chewed without any lateral movements of the mandible, snapping off the solid food and while drinking, he closed his mouth using mandible protrusion and tightening of the floor of oral cavity. The head was bent backwards. During the second phase, the swallowing act was enabled by the neck reclination and depression of the shoulders. The third phase of the swallowing act was characterized by the lower lip being pressured orally. At the same time, the tongue tip pressed on the lingual teeth surfaces, the tongue base elevated and using bilateral shoulder retraction, the bolus was swallowed.

\section{DISCUSSION}

The research project named "Verification of specific preventive program for mentally disabled people with combined impairments (NK 7438-3 IGA MH CR)" has been investigated over the years 2003-2005. This research project has been designed and based on a long-term experience of other authors $(1,2,12,13)$. Important fact introduced in this study was the evaluation of the quality of life of disabled in relation to their orofacial health. The quality of health has its medical and social aspects, which are studied both from objective and subjective point of view (14). The quality of life in disabled people is predominantly subjective and it is necessary to understand it as wellbeing of an individual (15). An individual approach to the disabled is an inevitable requirement for amelioration of their life. For these purposes it is important to educate the caregivers using advanced technologies (16). So far, this topic has not been included in pregradual curricula at medical faculties in the Czech Republic despite of its significancy (17). Orofacial health, its appropriate treatment and maintenance significantly contribute to the quality of life. Good oral health decreases the treatment needs in dentistry (18). This is why oral health was evaluated in this study. A short description of the study follows.

Oral health indices have been determined in 95 disabled children. Results of the basic study showed that oral health was poor - two thirds of the teeth were either untreated or treated by extraction therapy. A care for oral hygiene was incorrect. After the examination according to the Castillo Morales concept, which is used by many authors in different countries $(5,6)$, orofacial dysfunctions were found in $100 \%$ of children. The orofacial dysfunctions cause significant problems in different areas, but the most relevant are breathing, swallowing and verbal communication.

This article deals with the results of the above-mentioned study focused on swallowing difficulties and estimates of fluoride intake. With regard to fluorides intake, the urine fluoride concentrations were established (the main way of fluoride excretion) $(19,20,21)$. In order to reach comparability of fluorides exposition in children, the urine densities were measured and fluoride concentrations were extrapolated to the standard urine density $(1.020 \mathrm{~g} / \mathrm{ml})$. From the practical point of view, the extrapolation was not observed as relevant, but the urine density values were often found to be surprisingly high. This fact supports the hypothesis about the swallowing difficulties and insufficient liquids intake $(22,23)$. In this study, it has been proved that the atypical swallowing act and dependence of the liquids intake on the aid of another person are the main reasons of this situation.

The atypical swallowing act is a characteristic of disabled patients with combined impairments and it represents a very severe affection, which can influence the general health of the patients. That is the reason why the orofacial regulatory therapy is highly recommended to normalize the swallowing act. 
The ability to rinse the oral cavity and spit out is related to the swallowing act, too. If these functions are inadequate, certain amount of fluorides-containing toothpastes may be swallowed (9, $10,11)$. This is the reason why the fluoride concentrations in the urine were approaching the values of $0.9 \mathrm{mg} / \mathrm{l}$, which were the concentrations usually found during the period of water fluoridation in the Czech Republic (3). The situation could worsen if the carers would not respect the ability to rinse the mouth and would use toothpaste containing the same concentration of fluorides in all the patients (toothpastes for children contain from 250 to 500 ppm of fluoride; for juniors and adults from 1000 to $1500 \mathrm{ppm}$ of fluoride). The fluoride intake from toothpastes is decreased when tooth brushing is performed soon after meals $(19,20)$. It was described that toothpastes could contribute to the total fluoride intake in more than $66 \%(21)$.

Fig. 3 shows different ways in which children take liquids. The majority of the cohort needs some assistance with drinking. More than $10 \%$ of the children take liquids and foods from bottle and/or by spoon. These children are completely dependent on the help of other persons. The rest of the cohort could drink ad libitum anytime they wished, if the drinks were available. It means that even those children who could possibly drink by themselves did not drink.

\section{CONCLUSION}

- Results of this study confirm literature findings that orofacial dysfunctions influence liquids intake due to impaired function of facial muscles resulting into unpleasant feelings, difficulties or pain during the swallowing act.

- Concentrations of urine fluoride found in patients with orofacial dysfunctions reached the levels that used to be regularly found in the population during the period of water fluoridation in the Czech Republic. This is due to the swallowing of the fluorides-containing means of oral hygiene. High urine density was found in mentally ill children with orofacial dysfunctions reflecting inadequate liquids intake.

- Orofacial dysfunctions should be addressed on a public health level because they are related to a considerably large population group and they considerably decrease the quality of life. So far, this topic has not been included in pregradual curricula at medical faculties in the Czech Republic despite of its significancy.

\section{Acknowledgement}

The research project NK/7438-3 was supported by the IGA of the Ministry of Health of the Czech Republic.

\section{REFERENCES}

1. Limbrock GJ, Hoyer H, Scheying H. Drooling, chewing and swallowing dysfunctions in children with cerebral palsy, treatment according to Castillo Morales. J Dent Child. 1990 Nov-Dec;57(6):445-51.

2. Castillo-Morales R, Brondo J, Haberstock B. Orofacial Regulation Therapy. 2nd ed. Munich: Pflaum Publishing; 1998. (In German.)

3. Pilinová A, Polanecký V, Píša J, Šalandová M, Krutina M. Caries experience, oral health status and urine fluoride excretion in children in some localities in the Czech Republic. Cent Eur J Public Health. 2000 Feb;8(1):45-8.
4. Pilinová A, Lenčová E, Matejíčková E, Vojtěchová E. Oral health status of patients with disabilities in two localities in the Czech Republic. Spec Care Dentist. 2004 May-Jun; 24(3):167.

5. Castillo-Morales R, Brondo J, Hoyer H, Limbrock GJ. Treatment of chewing, swallowing and speech defects in handicapped children with Castillo-Morales orofacial regulator therapy: advice for pediatricians and dentists. Zahnarztl Mitt. 1985 May 1;75(9):935-42, 947-51. (In German.)

6. Hoyer H, Limbrock GJ. Orofacial regulation therapy in children with Down syndrome, using the methods and appliances of Castillo-Morales. ASDC J Dent Child. 1990 Nov-Dec;57(6):442-4.

7. Bardoděj Z, David A, Šedivec V, Škramovský S, Teisinger J. Exposure tests in industrial toxicology. Praha: Avicenum; 1980. (In Czech.)

8. Fejerskov O, Ekstrand J, Burt BA, editors. Fluoride in dentistry. 2nd ed. Copenhagen: Munksgaard; 1996.

9. Matejíčková E. Application of orofacial regulatory therapy in individuals with combined impairment with dysfunctions of orofacial system. Thesis. Bratislava: University of Komenský, Pedagogical faculty; 2004. (In Slovak.)

10. Korbmacher H, Limbrock J, Kahl-Nieke B. Orofacial development in children with Down's syndrome 12 years after early intervention with a stimulating plate. J Orofac Orthop. 2004 Jan;65(1):60-73.

11. Griffiths J, Boyle S. A colour guide to holistic oral care: a practical approach. London: Mosby; 1993.

12. Šalandová M, Pilinová A, Krutina M. Oral health care of disabled people in the Czech Republic. In: Abstracts from 3rd EADPH Congress; 1999 Sep 8-9; Strasbourg, France. Sheffield: BASCD; 1999. p. 25.

13. Šalandová M, Pilinová A, Krutina M. Monitoring of oral health status and treatment needs in mentally handicapped individuals with combined impairment in the Czech Republic. Final report of research project No. NK/4988-3 IGA of the Ministry of Health of the Czech Republic; 2000. (In Czech.)

14. Bencko V, Hnilicová $\mathrm{H}$, Klein O. Quality of life, sustainable future and medical education. Cent Eur J Public Health. 2005 Sep;13(3):112-6

15. Hnilicová H, Bencko V. Quality of life - defining the concept and its significance for medicine and health care. Prakt Lék. 2005;85(11):65660. (In Czech.)

16. Himelein MJ. A Student's Guide to Careers in the Helping Professions: online (HTML) version 1999 [document on the Internet]. The Office of Teaching Resources in Psychology; c1999-2004 [cited 2006 May 25]. Available from: http://www.lemoyne.edu/OTRP/otrpresources/helpingonline.html.

17. Bencko V. Hygiene and epidemiology in the public health. Tradition and present challenges in the Czech Republic. Zdrow Publiczne. 2001;111 (5-6):367-71.

18. Pilinová A, Polanecký V, Šalandová M, Mrklas L, Krejsa O, et al. Monitoring of caries experience and oral health status in school children in relation to the nutrition and fluorides exposure in selected regions of the Czech Republic. Final report of research project No. NK/4088-2 IGA of the Ministry of Health of the Czech Republic; 1998. (In Czech.)

19. Chan JC, O'Donnell D. Ingestion of fluoride dentifrice by a group of mentally handicapped children during toothbrushing. Quintessence Int. 1996 Jun;27(6):409-11.

20. Pessan JP, Pin ML, Martinhon CC, de Silva SM, Granjeiro JM, Buzalaf MA. Analysis of fingernails and urine as biomarkers of fluoride exposure from dentifrice and varnish in 4- to 7-year-old children. Caries Res. 2005 Sep-Oct;39(5):363-70.

21. Franco AM, Saldarriaga A, Martignon S, Gonzalez MC, Villa AE. Fluoride intake and fractional urinary fluoride excretion of Colombian preschool children. Community Dent Health. 2005 Dec;22(4):272-8.

22. Trulsson U, Klingberg G. Living with a child with a severe orofacial handicap: experiences from the perspectives of parents. Eur J Oral Sci. 2003 Feb;111(1):19-25.

23. Trier E, Thomas AG. Feeding the disabled child. Nutrition. 1998 Oct;14(10):801-5.

Received December 27, 2005 Received in revised form and accepted June 7, 2006 